\title{
A POLÍTICA DE ASSISTÊNCIA ESTUDANTIL NO IF BAIANO - CAMPUS TEIXEIRA DE FREITAS
}

http://dx.doi.org/10.5902/2318133820657

\author{
Maria Soares Cunha \\ Instituto Federal de Educação, Ciência e Tecnologia Baiano, Brasil.
}

\author{
Désirée Gonçalves Raggi \\ Instituto Federal de Educação, Ciência e Tecnologia do Espírito Santo, Brasil.
}

\begin{abstract}
Resumo
Este estudo apresenta resultados da investigação relacionada com a gestão da política de assistência estudantil realizada no Instituto Federal Baiano, campus de Teixeira de Freitas. Para alcançar os objetivos recorremos ao estudo de caso por meio de análise documental e entrevistas com servidores. A pesquisa está respaldada em Matias-Pereira (2012), Rosa (2015), Pacheco (2011), Piva (2011). Os resultados indicaram que os programas de assistência estudantil são bem administrados. No entanto, percebeu-se que a falta de alguns profissionais, como assistente social, pedagogo e psicólogo, prejudicam a operacionalização do Programa de Assistência e Inclusão Social do Estudante - Paise - e as ações pedagógicas. Constatou-se, ainda, que cerca de 5.628 auxílios foram pagos de 2012 até outubro de 2015, contribuindo com a inclusão social. Palavras-chave: assistência estudantil, inclusão social, institutos federais.
\end{abstract}

\section{STUDENT ASSISTANCE POLICY AT \\ IF BAIANO - CAMPUS TEIXEIRA DE FREITAS}

Abstract

This study investigates the management of student assistance policy held at the Instituto Federal Baiano, campus de Teixeira de Freitas. To achieve the objectives, we turn to the case study through the analysis of documents and interviews with the civil servants. The research is supported by: Matias-Pereira (2012), Rose (2015), Pacheco (2011), Piva (2011). The results indicated that the student assistance programs are well managed. However, it was noted that the lack of some professionals like social worker, educator and psychologist hurt the operationalization of Paise and pedagogical actions. It was also found that about 5628 aid was paid from 2012 until October 2015, thereby contributing to social inclusion.

Key-words: student assistance, social inclusion, federal institutes. 


\section{Introdução}

$\mathrm{O}$ Brasil apresenta um considerável crescimento econômico, visto que o índice do PIB em 2013 foi 0,744 , fato que possibilitou que o país ocupasse o 79ำ lugar no ranking mundial de desenvolvimento. Entretanto, existe uma boa parcela da população que se mantém abaixo da linha de pobreza, segundo dados do Instituto de Pesquisa Econômica Aplicada - Ipea. No ano de 2013 o país tinha um quantitativo de 10,45 milhões de cidadãos na extrema pobreza. Tais números revelam a desigualdade social presente na sociedade brasileira.

A elaboração de uma política pública ocorre em virtude de interesses comuns da sociedade e é regulada por ações estratégicas do governo que visam a intervir nas relações sociais. As políticas públicas existem para trazer satisfação das necessidades sociais, ou seja, visam a concretizar os direitos sociais, como saúde, educação, segurança, assistência, lazer, transporte. Na gestão das políticas públicas a avalição se faz essencial para diagnosticar os efeitos produzidos na comunidade e promover, se necessário for, o redimensionamento das ações e decisões adotadas.

Dentre as políticas públicas existentes no sistema educacional brasileiro destacamos as de assistência estudantil, pelas quais se busca diminuir os indicadores de repetência, evasão e exclusão e promover a democratização e autonomia na gestão das escolas públicas. Entendemos que o acesso à educação é um dos principais fatores que contribuem para a conquista de melhores oportunidades profissionais e que é um meio capaz de proporcionar diminuição das desigualdades.

Por entendermos a importância desse tema surgiu o interesse em analisar as políticas públicas de assistência estudantil com o intuito de diagnosticar como as mesmas têm sido administradas, uma vez que ainda não se realizaram pesquisas nesse campo no âmbito do IF Baiano de Teixeira de Freitas. Essa investigação nos permitiu conhecer como o instituto concretiza as ações e possibilita questionar, opinar e colaborar com a sua consolidação e ampliação.

\section{Procedimentos metodológicos}

Em busca dos resultados elencamos o estudo de caso como estratégia de investigação. $O$ estudo de caso é profundo e exaustivo de um ou poucos objetos, de maneira que permita seu amplo e detalhado conhecimento (Gil, 2002). Como este estudo de caso é único, ele é classificado como holístico, ou seja, possui apenas uma unidade de análise. O problema da pesquisa consiste em observar como é administrada a política de assistência estudantil do IF Baiano, campus de Teixeira de Freitas.

O Instituto Federal de Educação, Ciência e Tecnologia Baiano, campus de Teixeira de Freitas, fica localizado na BR101, km 882, foi criado pela lei n. 11.892, de 29/12/2008, e existe desde 2010, a partir da nomeação do diretor geral pró-tempore.

Assim, para respaldar o estudo foi feito um levantamento bibliográfico com o intuito de apresentar fundamentos teóricos para sustentar e conceituar os principais temas. Por conseguinte, foi desenvolvida a análise detalhada dos documentos oficiais, leis e editais referentes à assistência estudantil.

Para alcançar a coleta de dados utilizamos a observação sistemática da instituição, sob a autorização da direção, e um formulário, técnica de coleta de dados em que o pesquisador formula questões previamente elaboradas e anota as respostas (Gil, 2002). 
Uma amostra de 25 servidores, totalizando $36 \%$ do universo da pesquisa, dentre 23 técnicos administrativos e 46 docentes, responderam um formulário com nove questões, contendo perguntas fechadas e duas abertas, com o objetivo de verificar como os servidores percebem a administração do Programa de Assistência e Inclusão Social do Estudante - Paise - no campus. Finalmente analisamos os dados coletados, tabulamos as informações e as interpretamos.

\section{Políticas de assistência estudantil no IF baiano de Teixeira de Freitas}

As políticas públicas são criadas com o objeto de resolver problemas sociais, sempre em prol da coletividade e do desenvolvimento, promovendo escolarização, conhecimento, saúde, serviços essenciais, que satisfaçam a inclusão sociopolítica e econômica. Nesse contexto é válido destacar os objetivos das políticas públicas:

Preocupação em corrigir as desigualdades sociais e promover o desenvolvimento sustentável. Assim, as políticas públicas se apresentam como instrumentos relevantes de execução de programas políticos de intervenção estatal na sociedade, com o propósito de propiciar igualdade de oportunidades aos cidadãos, objetivando assegurar-lhes as condições materiais mínimas para uma existência digna. (Matias; Pereira, 2012, p. 82)

Assim, as políticas públicas são ações de intervenção do Estado na sociedade pelas quais se busca promover as necessidades básicas e intervir nos problemas sociais. As políticas públicas devem ser avaliadas, pois isso possibilita o monitoramento e comparações, o que pode contribuir com a melhoria da gestão.

É válido ressaltar que, dentre as ações afirmativas de assistência estudantil que buscam promover inclusão social, merece destaque a expansão dos institutos federais que iniciou no Brasil no ano de 2008, a partir da lei n. 11.892, com o objetivo de oferecer ações inclusivas na área de formação profissional, a fim de promover educação gratuita e de qualidade, equidade e justiça social, com a interiorização do ensino e contribuir com o desenvolvimento local. Em virtude da localização e abrangência dos institutos federais surgiu a necessidade dos gestores públicos das instituições de ensino profissional efetivarem as políticas de assistência estudantil, a fim de materializar as condições que viabilizarão a inserção da população em situação de vulnerabilidade socioeconômica.

Para tanto, precisam promover a assistência estudantil adequada para que jovens e adultos pertencentes às classes desfavorecidas possam acessar, permanecer e concluir sua formação:

A inserção dos estudantes, em situação de vulnerabilidade social e econômica, em programas de assistência estudantil pode contribuir na permanência e êxito deles nas instituições de educação no Brasil, tendo em vista as atividades escolares que demandam recursos financeiros, tais como: custeio de vale-transporte, alimentação, material didático, fotocópias, taxas de inscrições de cursos e participação em eventos escolares, moradia, entre outros. (Rosa, 2015, p. 121)

A implantação de políticas de assistência estudantil pode vir a contribuir com o acesso, pelas cotas, com a permanência, por meio da oferta de auxílios moradia, alimentação, materiais escolares, transporte e creche e o êxito dos estudantes, com a 
oferta de acompanhamento pedagógico, social, atendimento à saúde, cultura, esporte e lazer. Podem, também, colaborar com a formação de cidadãos críticos e atuantes, capazes de fortalecer o desenvolvimento local.

A assistência estudantil do IF Baiano, prevista no Plano de Desenvolvimento Institucional, foi aprovada pela resolução n. 4, de 29 de março de 2011, e conta com vários programas, dentre eles: Programa de Assistência e Inclusão Social do Estudante Paise -; Programa de Apoio à Diversidade e Ações Afirmativas - Proada; Programa de Assistência Integral à Saúde - Pro-Saúde; Programa de Acompanhamento Psicossocial e Pedagógico; Programa de Incentivo à Cultura, Esporte e Lazer - Pincel; e Programa de Incentivo à Participação Político-Acadêmica - Propac.

No entanto, o programa de maior relevância no campus é o Programa de Assistência e Inclusão Social do Estudante - Paise -, que, além do decreto n. 7.234/2010, também está pautado no decreto n. 7.416, de 30 de dezembro de 2010, que trata da concessão de bolsas para desenvolvimento de atividades e contribuir com a permanência do aluno.

O IF Baiano de Teixeira de Freitas oferece cursos profissionalizantes integrados ao ensino médio: Administração, Agropecuária e Florestas; e subsequentes ao ensino médio: Administração, Agropecuária, Florestas e Hospedagem. Atende, aproximadamente, a 733 estudantes:

O foco dos Institutos Federais é a promoção da justiça social, da equidade, do desenvolvimento sustentável com vistas à inclusão social, bem como a busca de soluções técnicas e a geração de novas tecnologias. Essas instituições devem responder, de forma ágil e eficaz, às demandas crescentes por formação profissional, por difusão de conhecimentos científicos e de suporte aos arranjos produtivos locais. (Pacheco, 2011, p. 49)

Em relação aos institutos federais observamos que $68 \%$ dos servidores consideram os institutos federais uma política pública que efetivamente promove inclusão social da população em situação de vulnerabilidade socioeconômica.

É válido destacar que o processo seletivo de ingresso fere a missão dos institutos federais que é pautada na promoção de justiça social, da equidade e da inclusão social, pois reduz as oportunidades de acesso do candidato. Como exemplo podemos citar o processo seletivo do Instituto Federal de Educação, Ciência e Tecnologia do Rio Grande do Sul, campus de Sertão, que a partir da unificação da data do processo seletivo gerou impacto social, pois diminuiu as chances de ingresso do candidato: "Essa forma de tratamento do processo seletivo está em discordância com os objetivos dos Institutos Federais, as quais foram criados para ampliar o acesso dos estudantes a cursos profissionalizantes" (Piva, 2011, p. 38).

No IF Baiano de Teixeira de Freitas a política de assistência estudantil é realizada, prioritariamente, pelo Programa de Assistência e Inclusão Social do Estudante - Paise - e administrada pela Coordenação de Assuntos Estudantis - CAE. A CAE é uma equipe formada por um docente, três assistentes de alunos e um nutricionista. Administra ações voltadas aos estudantes, em especial o refeitório que oferece quatro refeições diárias. 
O Paise existe no campus desde 2011. O programa oferece uma série de auxílios aos estudantes regularmente matriculados em situação de vulnerabilidade social por meio de um processo seletivo normatizado por edital, a cada ano, e são pagas 10 bolsas durante $o$ ano letivo. Para continuar recebendo o apoio o estudante precisa apresentar frequência mínima e continuar em situação de vulnerabilidade social.

Constatou-se, ainda, que cerca de 5.628 auxílios foram pagos de 2012 até outubro de 2015 e que tais auxílios contribuíram com a inclusão social da maioria dos alunos em situação de vulnerabilidade social. O benefício é oferecido desde 2011, mas o quantitativo desse período não foi encontrado e, em relação a 2015, só teremos o total ao final do ano letivo.

Em 2015 um total de 188 alunos foram contemplados no processo seletivo com os auxílios do Paise. A tabela 1 mostra os auxílios oferecidos no corrente ano, seus respectivos valores e a quantidade de bolsas contempladas.

Tabela 1 -

Tipos de auxílios, valor e bolsas concedidas no âmbito do Paise em 2015.

\begin{tabular}{|c|c|c|}
\hline Auxílio & Valor & Bolsas \\
\hline Alimentação & 300,00 & 6 \\
\hline Creche & 300,00 & 5 \\
\hline Moradia & 350,00 & 24 \\
\hline Transporte (urbano) & 150,00 & 71 \\
\hline Transporte (rural) & 250,00 & 24 \\
\hline Permanência & 300,00 & 8 \\
\hline Cópia e impressão & cota & 50 \\
\hline
\end{tabular}

Ao serem questionados se os auxílios oferecidos pelo Paise contemplam os alunos em situação de vulnerabilidade socioeconômica da instituição, 52\% asseveraram que contemplam parcialmente, pois os recursos são insuficientes para atender à demanda de alunos que estejam em risco de vulnerabilidade social e não contemplam todos aqueles que necessitam.

Em 2015 o orçamento destinado ao Paise foi liberado no mês de maio, entretanto, o mesmo só pode ser usufruído depois do resultado do processo seletivo. $O$ edital foi elaborado e divulgado no mês de maio, o resultado saiu em junho e as bolsas só começaram a ser pagas no mês de agosto. Tal atraso prejudicou os alunos que dependem dos auxílios para frequentar as aulas e se dedicar aos estudos. Vale ressaltar que o atraso da lei orçamentária anual do governo federal em 2015 teve importante influência na demora de liberação e repasse do Paise.

Quando perguntados se os valores dos auxílios descritos na tabela 1 são suficientes para atender às necessidades dos alunos, $52 \%$ dos investigados consideram que sim, $48 \%$ avaliam que contemplam parcialmente.

O Programa Nacional de Assistência Estudantil, decreto n. 7.234, de 19/07/2010, é uma política educacional que regulamenta a política de assistência estudantil do ensino de nível superior e profissionalizante. Tem como finalidade ampliar as condições de permanência, minimizando os efeitos das desigualdades, reduzindo a evasão e retenção, contribuindo assim, com a promoção da inclusão social pela escolarização. 
Foi indagado se o programa de assistência estudantil contribui com a inclusão social, permanência e êxito dos estudantes na instituição: 64\% dos servidores declaram que contribui e $36 \%$ registraram que contribui parcialmente, como pode ser observado no gráfico 1.

Gráfico 1 -

Paise: inclusão social, permanência e êxito.

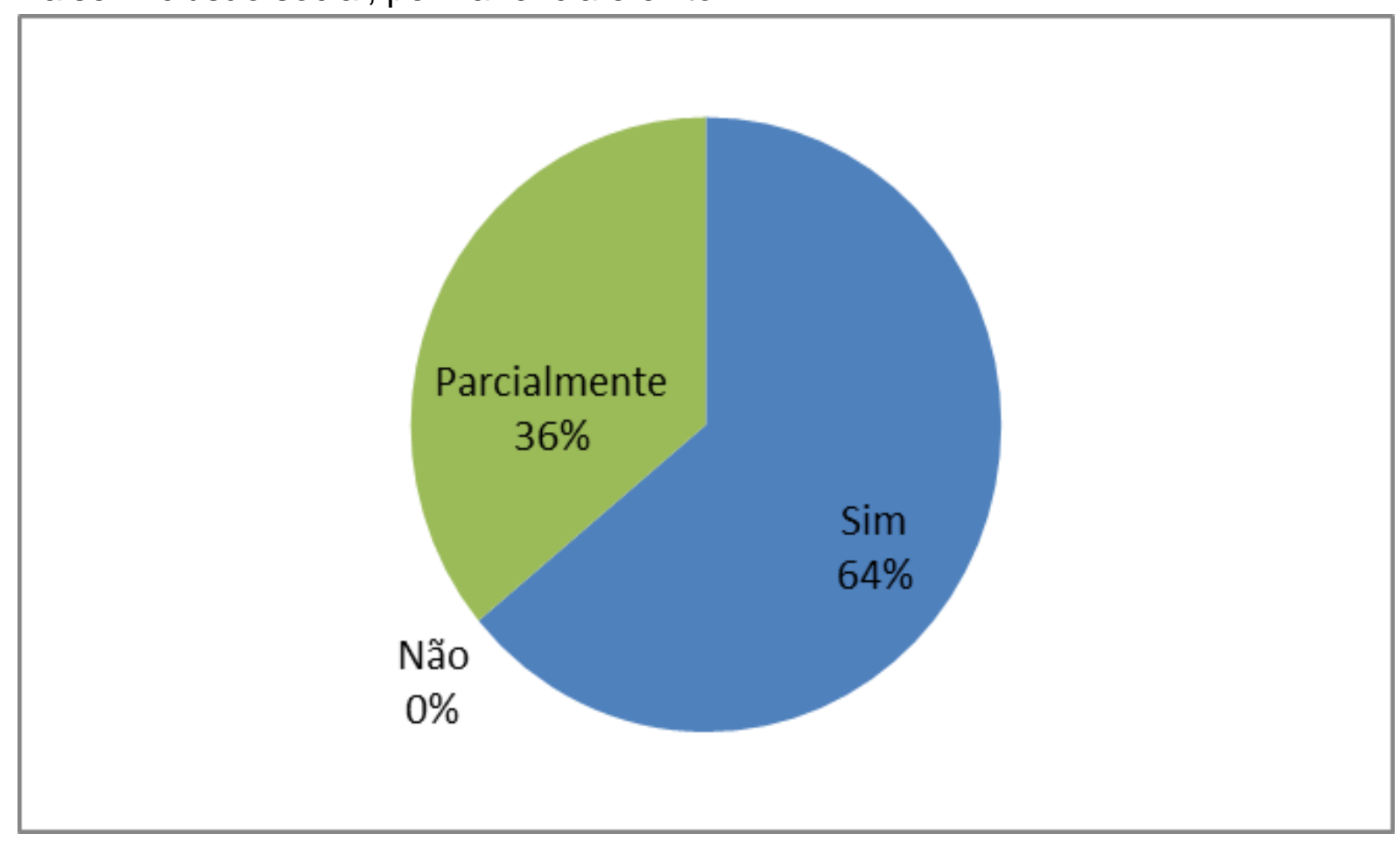

Para Matias-Pereira (2012) a qualidade da gestão das políticas públicas é essencial para a realização da justiça social e a avaliação é primordial para o seu sucesso. $\mathrm{Na}$ avaliação as ações são retroalimentadas, os resultados e impactos são mensurados com o intuito de observar a alteração na qualidade de vida da comunidade beneficiada. Assim, a avaliação da gestão das políticas públicas busca promover, se necessário, o redimensionamento das ações e decisões adotadas.

Como a avaliação é essencial para o sucesso da política pública, os investigados expressaram sua opinião em relação à administração da política de assistência estudantil no IF Baiano, campus de Teixeira de Freitas: $92 \%$ dos servidores consideram que a divulgação do Paise é efetiva e que o programa é bem administrado. Portanto, a gestão da política pública de assistência estudantil do IF Baiano de Teixeira de Freitas tem atendido aos seus objetivos, mesmo dispondo de uma quantidade insuficiente de profissionais, em especial a ausência de um assistente social.

Em face das contribuições dos servidores algumas deficiências foram destacadas, entre elas a questão do campus enfrentar deficiência em relação ao quadro de funcionários, pois não dispõe de assistente social, pedagogo, psicólogo, enfermeiro, médico e dentista, o que dificulta o atendimento dos alunos e a possibilidade de realizar um monitoramento e evidenciar de forma efetiva a vida escolar e a situação de fragilidade social do corpo estudante. 
Dentre as sugestões dos pesquisados para o Paise podemos destacar a necessidade de acelerar a liberação dos recursos por parte do governo federal, oferecer um valor maior destinado a este programa, ampliar a quantidade de bolsas por categorias, convocar mais profissionais da área de assistência social e oferecer acompanhamento contínuo da vida social de cada estudante.

\section{Considerações finais}

Dentre os programas de assistência estudantil implantados pelo campus o de maior destaque é o Programa de Assistência e Inclusão Social do Estudante, que está presente no campus Teixeira de Freitas desde 2011 e que, atualmente, é administrado pela Coordenação de Assuntos Estudantis. Para fazer jus a um determinado auxílio o aluno precisa passar por um processo seletivo anual, estar regulamente matriculado, ter renda per capita de até um salário mínimo e meio e estar em condição de vulnerabilidade social. Para manter a continuidade da bolsa o estudante precisa apresentar frequência mínima de $85 \%$, rendimento acadêmico satisfatório, bom comportamento e situação de

vulnerabilidade social. Portanto, a gestão do Programa de Assistência e Inclusão Social do Estudante do IF Baiano, campus de Teixeira de Freitas, é considerada pelos entrevistados como de qualidade.

Os auxílios ofertados pelo Paise - moradia, alimentação, cópia e impressão, transporte, creche, permanência e eventual - proporcionam condições para que os estudantes contemplados possam efetivar seus estudos. Com os objetivos de democratizar as condições de permanência, diminuir as desigualdades sociais e regionais, reduzir a evasão e promover a inclusão social o Paise pagou 5.628 bolsas de 2012 até outubro de 2015. Nesse sentido os auxílios contribuíram com a inclusão social de uma grande parte dos estudantes de baixa renda e em situação de vulnerabilidade social.

Entretanto, percebeu-se que a falta de alguns profissionais, como assistente social, pedagogo, psicólogo e enfermeiro prejudica algumas ações da instituição como o acompanhamento pedagógico, social e o atendimento à saúde. Em face disso se faz necessária a disponibilização do código de vagas pelo Ministério da Educação para a contratação de novos servidores. Uma equipe com os profissionais citados possibilitaria um diagnóstico do contexto social do estudante mais completo, o que contribuiria com uma melhor intervenção, articulação e execução dos programas de assistência estudantil.

\section{Referências}

BRASIL. Decreto n. 7.416 de 30 de dezembro de 2010. Disponível em <file:///C:/Users/Maria/Documents/Artigo\%20disserta\%C3\%A7\%C3\%A3o/Dados\%200\%2 0IF/Decreto\%20n\%C2\%BA\%207416.html>. Acesso em 5 jul. 2015.

BRASIL. Lei n. 11.892, de 29 de dezembro de 2008. Disponível em: <http://www.planalto.gov.br/ccivil 03/ ato2007-2010/2008/lei//11892.htm>. Acesso: 02/07/2015.

BRASIL. Programa Nacional de Assistência Estudantil - Pnaes. Decreto n. 7.234, de 19 de julho de 2010. Disponível em <http://www.planalto.gov.br/ccivil 03/ Ato20072010/2010/Decreto/D7234.htm>. Acesso em 3 jul. 2015.

GIL, Antonio Carlos. Como elaborar projetos de pesquisa. São Paulo: Atlas, 2002. 
IPEA - Instituto de Pesquisa Econômica Aplicada, 2013. Disponível em: $<$ http://www.ipea.gov.br/portal/>. Acesso em 8 jul. 2015.

MALIK, Khalid. Relatório do desenvolvimento humano 2014: sustentar o progresso humano, reduzir as vulnerabilidade e reforçar a resiliência. Nova lorque: ONU/Pnud, 2014.

MATIAS-PEREIRA, José. Curso de gestão estratégica na administração pública. São Paulo: Atlas, 2012.

PACHECO, Eliezer (org.). Os institutos federais: uma revolução na educação profissional e tecnológica. São Paulo: Moderna, 2011.

PIVA, Maqueli Elizabete. Educação profissional e assistência estudantil nos cursos técnicos: um estudo de caso no IFRS campus de Sertão. Seropédica: UFRRJ, 2011. $73 f$. Dissertação (mestrado em Ciências). Universidade Federal Rural do Rio de Janeiro.

ROSA, Ana Claudia Ferreira. AMORIM, Janaína Miranda Muradás. MACEDO, Lívia Fernanda Leal. Contextualização no Instituto Federal do Tocantins na esfera das políticas de educação profissional e tecnológica. Regae - Revista de Gestão e Avaliação Educacional, Santa Maria, v. 4, n. 7, 2015, p. 113-126.

Maria Soares Cunha é mestre em Gestão Social, Educação e Desenvolvimento Regional pela Faculdade Vale do Cricaré/ES, especialista em Gestão Pública pela Uneb/UAB e coordenadora da Secretaria de Registros Acadêmicos do Instituto Federal de Educação, Ciência e Tecnologia Baiano, campus de Teixeira de Freitas. Endereço: Rua José do Patrocínio, 320/202 - 45992-006 - Teixeira de Freitas - BA Brasil.

E-mail: biacunha@hotmail.com.

Désirée Gonçalves Raggi é doutora em Educação pela Universidad del Norte. Endereço: Rua Gastão Roubach, 130/702 - 29101020 - Vila Velha - ES - Brasil. E-mail: desireeraggi@yahoo.com.br.

Recebido em 8 de dezembro de 2015.

Aceito em 27 de maio de 2016. 